\title{
AVALIAÇÃO E EFEITO DA COMPACTAÇÃO DO SOLO, DEVIDO À FREQÜÊNCIA DE TRÁFEGO, NA PRODUÇÃo DE MADEIRA DE EUCALIPTO ${ }^{1}$
}

\author{
Fernando Seixas² e Cíntia Rodrigues de Souza ${ }^{3}$
}

\begin{abstract}
RESUMO - A compactação do solo devido ao tráfego de máquinas de colheita de madeira, assim como a extensão da área impactada, constitui fator de preocupação, em virtude da possibilidade de efeitos prejudiciais para o crescimento da floresta. O objetivo deste trabalho foi avaliar os efeitos da frequiência de tráfego de um trator mais carreta na compactação do solo e na produtividade de um plantio de Eucalyptus grandis, no final da primeira rotação de sete anos. A compactação do solo, avaliada por meio da densidade e resistência à penetração, foi determinada para tratamentos com 1, 3, 5, 10 e 20 passadas do veículo carregado com 12,5 estéreos de madeira, com peso total de oito toneladas, além de uma testemunha sem a ocorrência de tráfego. Após as cinco primeiras passadas ocorreram cerca de $80 \%$ do adensamento total do solo, resultante das 20 passadas, sendo recomendado restringir o tráfego de veículos dentro do talhão na menor área possível, diminuindose a extensão de possíveis efeitos da compactação sobre o povoamento florestal. Contudo, nessa situação em particular a compactação do solo não prejudicou o crescimento das árvores em nenhum dos tratamentos avaliados.
\end{abstract}

Palavras-chave: Extração de madeira, trator florestal e controle de tráfego.

\section{EVALUATION AND EFFECT OF SOIL COMPACTION DUE TO TRAFFIC FREQUENCY ON EUCALYPTUS WOOD PRODUCTION}

\begin{abstract}
Soil compaction resulting from forestry machine traffic may reduce forest production. The objective of this study was to evaluate the influence of traffic frequency on soil compaction and Eucalyptus grandis forest productivity after a seven-year rotation. Soil bulk density and cone penetrometer resistance measurements were used as indicators to evaluate soil compaction resulting from tractor plus trailer traffic, a total of 8 tons load, after 1, 3, 5, 10, 20 vehicle passes and a control with no traffic. Around 80\% of total soil compaction after 20 vehicle passes resulted after the first five vehicle passes, with no significant change after that. This indicates the necessity to restrict vehicle traffic to smaller areas in the forest, even with that area reaching higher compaction levels, but reducing the extension of compacted soil. Nevertheless, on this particular situation, soil compaction in all treatments did not reduce Eucalyptus productivity.
\end{abstract}

Keywords: Wood forwarding, forestry tractor and traffic control.

\section{INTRODUÇÃO}

Uma das maneiras de se diminuir o impacto da compactação dos solos em um plantio florestal é a restrição ao tráfego de veículos por toda a área, concentrando-o em carreadores pré-designados. Essa recomendação é corroborada por estudos que afirmam que a maior parte do aumento da densidade do solo já ocorre durante as primeiras passadas de uma máquina. Dessa maneira, a concentração do tráfego em trilhas pre-determinadas não implicaria aumento significativo na compactação, já que o maior e inevitável impacto já teria ocorrido após as primeiras passadas da máquina.

\footnotetext{
${ }^{1}$ Recebido em 28.08.2006 e aceito para publicação em 21.06.2007.

${ }^{2}$ Departamento de Ciências Florestais da ESALQ/USP, Cx. Postal 9, 13418-900 Piracicaba-SP. E-mail: <fseixas@esalq.usp.br>.

${ }^{3}$ Embrapa Amazônia Ocidental, Rod. Am-10 km 29, Manaus, AM.
} 
Hatchell et al. (1970) analisaram 47 locais de exploração, concluindo que a maior parte da compactação ocorreu com as três primeiras passadas do "skidder". Em outro estudo feito em um Latossolo VermelhoAmarelo, a compactação do solo aumentou com o maior número de passadas de um "forwarder", com 42,3 t de peso total carregado, atingindo, após 11 passadas, $74 \%$ da compactação final resultante de 25 passadas do trator, não tendo sido significativa após uma passada (SEIXAS et al., 2003a). Já na análise da compactação, causada também em outro Latossolo Vermelho-Amarelo, devido ao tráfego de um "skidder" de garra, pesando 13,5 t, e mais 4,0 t de um feixe de árvores, observouse que a compactação após cinco passadas do trator representou cerca de $75 \%$ em média do nível máximo de compactação, atingido no perfil até $15 \mathrm{~cm}$ abaixo da superfície do solo, após um total de 25 passadas (SEIXAS et al., 2003b).

No caso de reflorestamentos, o módulo utilizado de colheita de madeira condiciona o porcentual da área que será atingida pelo deslocamento das máquinas. Segundo Fenner (2002), a utilização de "feller-buncher" e "skidder" implica que, praticamente, toda a área sofrerá tráfego pelo menos uma vez. Já no emprego do módulo “harvester - forwarder", o tráfego ficará concentrado nos ramais de extração de madeira, com a área trafegada dependendo da distância entre eles.

Estudo feito por Seixas et al. (2003a), com a instalação de aparelho GPS em um "forwarder", concluiu que a movimentação do trator, na extração de madeira de povoamento de eucalipto em corte raso, foi feita de maneira concentrada em um quarto da área experimental. Em outro acompanhamento feito com o GPS instalado em um "skidder", o tráfego efetivo do rodado ocorreu em $30 \%$ da área plantada, mas $85 \%$ da área total apresentou algum tipo de distúrbio do solo causado também pelo arraste do feixe de árvores (SEIXAS et al., 2003b).

Com o intuito de contribuir com informações científicas para uma possível adoção do controle de tráfego em povoamentos florestais, em condições tropicais de solo e clima, o objetivo deste trabalho foi avaliar os efeitos da freqüência de tráfego de um trator "florestal", utilizado na extração de madeira, na compactação do solo e na produtividade de um plantio de eucalipto, ao final da primeira rotação de sete anos.

R. Árvore, Viçosa-MG, v.31, n.6, p.1047-1052, 2007

\section{MATERIAL E MÉTODOS}

\subsection{Local}

Povoamento de Eucalyptus grandis, com espaçamento de $3 \times 2 \mathrm{~m}$, plantado na Estação Experimental de Itatinga, SP, pertencente à Escola Superior de Agricultura "Luiz de Queiroz". A análise textural do solo do local do experimento apresentou os seguintes resultados: argila (10\%), silte (2\%), areia grossa $(2 \%)$, areia média (32\%) e areia fina $(54 \%)$.

\subsection{Equipamentos}

Foram empregados os seguintes equipamentos na realização do estudo: trator agrícola mais carreta carregada (12,5 st), totalizando $8.000 \mathrm{~kg}$, para simulação do tráfego no talhão; martelo AMS para coleta de amostras indeformadas de solo para o cálculo da densidade; e penetrômetro de impacto para determinação da resistência à penetração do solo.

\subsection{Variáveis analisadas}

As amostras de solo para cálculo da densidade foram coletadas com martelo de solo AMS, com anéis de $5 \mathrm{~cm}$ de diâmetro e $5 \mathrm{~cm}$ de altura, em duas profundidades: 5,0-10,0 cm e 12,5-17,5 cm. Dez amostras foram coletadas anteriormente ao tráfego, por tratamento e profundidade, ao longo da localização estimada do centro dos sulcos do rodado da carreta, e mais 10 após a efetivação do tráfego do trator. $\mathrm{O}$ peso de matéria seca em estufa $\left(24 \mathrm{~h}\right.$ a $\left.105{ }^{\circ} \mathrm{C}\right)$ das amostras de solo foi utilizado para expressar a densidade como peso/ unidade de volume $\left(\mathrm{g} . \mathrm{cm}^{-3}\right)$.

Um penetrômetro de impacto foi usado para medir a resistência do solo à penetração até a profundidade de $60 \mathrm{~cm}$. Todas as leituras, nas situações com e sem tráfego, foram feitas em um período muito próximo, evitando-se alterações no teor de água do solo. Realizaram-se 20 leituras de cada situação por tratamento, com o pré-tratamento localizado próximo ao sulco resultante do tráfego e o pós-tratamento no centro do sulco. O número de impactos do penetrômetro foi transformado em $\mathrm{kPa}$, por meio da fórmula desenvolvida por Stolf (1991):

$$
\mathbf{R}=560+689 \mathbf{N}
$$

em que:

$$
\begin{aligned}
& \mathrm{R}=\text { resistência do solo à penetração em } \mathrm{kPa} ; \mathrm{e} \\
& \mathrm{N}=\text { número de impactos por decímetro. }
\end{aligned}
$$




\subsection{Delineamento experimental}

Os seguintes tratamentos foram analisados neste estudo:

* Tratamento 1: 1 passada do veículo sobre o solo.

* Tratamento 2: 3 passadas do veículo sobre o solo.

* Tratamento 3: 5 passadas do veículo sobre o solo.

* Tratamento 4: 10 passadas do veículo sobre o solo.

* Tratamento 5: 20 passadas do veículo sobre o solo.

* Testemunha: sem tráfego.

Cada tratamento correspondeu a uma parcela de $5 \mathrm{~m}$ de largura e $80 \mathrm{~m}$ de comprimento, abrangendo uma linha de 40 árvores, com duas repetições por tratamento. Estes foram separados entre si por três linhas de árvores. O veículo trafegou "encavalado" sobre a linha de árvores, compactando simultaneamente as duas laterais. Cada parcela englobou duas faixas de tráfego (esquerda e direita), onde foram coletadas as amostras de solo e feitas as leituras com o penetrômetro. A análise estatística seguiu o padrão de experimento em blocos casualizados, com três blocos e seis tratamentos por bloco, sendo o tratamento 6 (testemunha) considerado somente na avaliação final, feita após sete anos do plantio, para verificar a influência da freqüência do tráfego do trator de extração de madeira sobre a produtividade florestal.

\section{RESULTADOS E DISCUSSÃO}

\subsection{Densidade do solo}

O incremento máximo de densidade do solo neste estudo foi de 7,0\%, registrado na profundidade de 5,0 a 10,0 cm após 10 passadas do veículo (Tabela 1), e o nível de compactação considerado prejudicial está por volta de um acréscimo entre 15 e $20 \%$ no valor inicial da densidade média do solo (GEIST et al., 1989).

De acordo com a análise estatística, na profundidade de 5,0 a $10,0 \mathrm{~cm}$ somente o tratamento 1 diferenciouse dos demais. Todos os outros tratamentos não apresentaram diferença estatisticamente significativa no nível de $5 \%$ de probabilidade. Na profundidade de 12,5 a $17,5 \mathrm{~cm}$, os tratamentos 1 e 2 não apresentaram diferença estatística entre si, mas o tratamento 1 diferiu de todos os outros, também no nível de 5\% de probabilidade. Isso indica que o tráfego de veículos não exerceu muita influência na densidade do solo a partir do tratamento 3, ou seja, cinco passagens sobre o solo. Em outras palavras, aproximadamente $80 \%$ da variação de compactação do solo nas duas profundidades, detectada por meio da densidade, ocorreram depois de cinco passadas do trator sobre o mesmo local.

\subsection{Resistência à penetração do solo}

As desvantagens do uso do penetrômetro, em comparação com a determinação da densidade do solo, incluem a influência da presença de raízes e pedras no solo, e os efeitos do teor de água do solo nas leituras, cuja diminuição geralmente implica aumento da resistência ao penetrômetro. A penetração de raízes de espécies florestais é geralmente dificultada em resistências do solo a partir da faixa entre 2,5 e 3,0 MPa (GREACEN e SANDS, 1980; SANDS et al., 1979). O baixo teor médio de água do solo $(6,5 \%)$, encontrado durante a realização do estudo, refletiu os valores próximos ao limite no solo que não sofreu tráfego, mas, ainda

Tabela 1 - Valores médios de densidade $\left(\mathrm{g} . \mathrm{cm}^{-3}\right)$ dos diferentes tratamentos, antes (Dens. Pré) e depois do tráfego (Dens. Pós) do veículo, nas profundidades de 5,0 a $10,0 \mathrm{~cm}$ e de 12,5 a $17,5 \mathrm{~cm}$

Table 1 - Bulk density averages $\left(\right.$ g. $\left.\mathrm{cm}^{-3}\right)$ for pre-(Dens. Pre) and post-treatment ( Dens. Pos) at 5.0-10.0 cm and 12.5$17.5 \mathrm{~cm}$ depth

\begin{tabular}{|c|c|c|c|c|c|c|}
\hline \multirow{3}{*}{ Tratamento } & \multicolumn{6}{|c|}{ Profundidade } \\
\hline & \multicolumn{3}{|c|}{$5,0-10,0 \mathrm{~cm}$} & \multicolumn{3}{|c|}{$12,5-17,5 \mathrm{~cm}$} \\
\hline & Dens. Pré & Dens. Pós & $\Delta *$ & Dens. Pré & Dens. Pós. & $\Delta$ \\
\hline \multicolumn{4}{|c|}{ g.cm ${ }^{-3}$} & \multicolumn{3}{|c|}{ g.cm-3 } \\
\hline 1 & 2,07 & 2,09 & $0,02 \mathbf{a}$ & 2,07 & 2,08 & $0,01 \mathbf{a}$ \\
\hline 2 & 2,04 & 2,14 & $0,10 \mathbf{b}$ & 2,04 & 2,13 & $0,09 \mathbf{a b}$ \\
\hline 3 & 2,07 & 2,19 & $0,12 \mathbf{b}$ & 2,07 & 2,17 & $0,10 \mathbf{b}$ \\
\hline 4 & 2,02 & 2,16 & 0,14 b & 2,03 & 2,15 & $0,12 \mathbf{b}$ \\
\hline 5 & 2,09 & 2,21 & $0,12 \mathbf{b}$ & 2,05 & 2,19 & $0,14 \mathbf{b}$ \\
\hline
\end{tabular}

(*) Incremento na densidade do solo após o tráfego do trator. Valores seguidos de mesma letra são semelhantes entre si, no nível de 5\% de probabilidade. 
assim, os resultados após o tráfego indicaram claramente a dificuldade quanto à possibilidade de expansão do sistema radicular naquela situação. Essa condição atingiu o seu ponto mais crítico após 20 passadas do veículo, com valores de resistência ao redor de 7,0 MPa nos $20 \mathrm{~cm}$ superficiais do solo, no tratamento 5 (Figura 5).

A análise estatística para resistência à penetração apresentou resultados semelhantes aos encontrados para densidade, não registrando diferença significativa entre os tratamentos 3 (Figura 3), 4 (Figura 4) e 5, reforçando a indicação de que a maior parte da influência do tráfego de veículos sobre a compactação do solo ocorreu após a efetivação de cinco passadas do veículo. A partir de $40 \mathrm{~cm}$ de profundidade, somente os tratamentos 1 (Figura 1) e 5 diferiram entre si, não havendo mais influência do número de passagens do veículo na compactação do solo depois dessa profundidade.

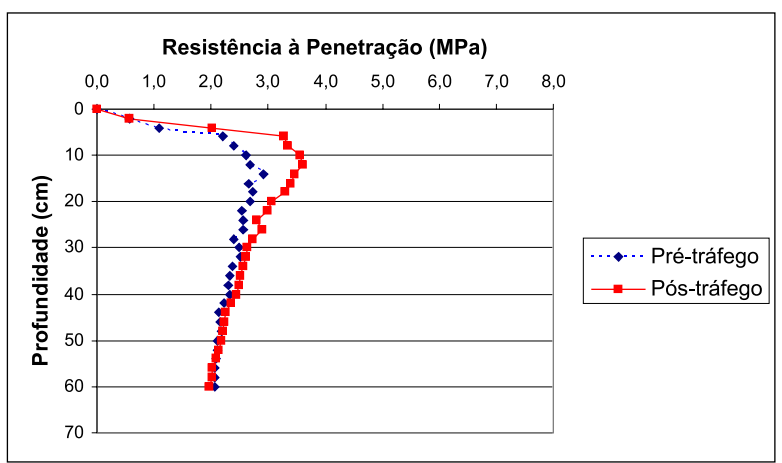

Figura 1 - Resistência à penetração do solo (MPa) após uma passada do trator + carreta.

Figure 1 -Cone penetrometer resistance (MPa) after 1 tractor + trailer pass.

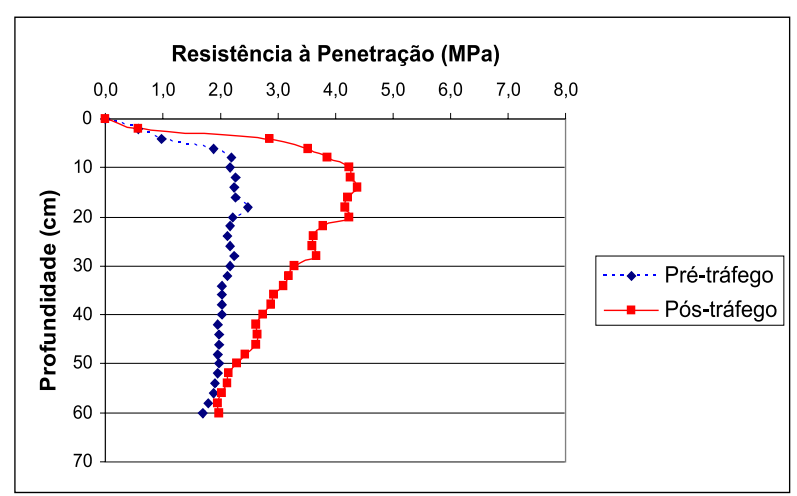

Figura 2 - Resistência à penetração do solo $(\mathrm{MPa})$ após três passadas do trator + carreta.

Figure 2 - Cone penetrometer resistance (MPa) after 3 tractor + trailer passes.

R. Árvore, Viçosa-MG, v.31, n.6, p.1047-1052, 2007

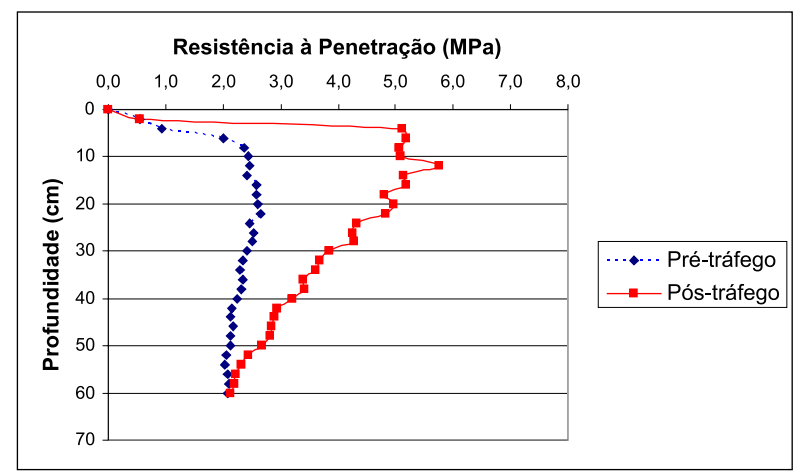

Figura 3 - Resistência à penetração do solo (MPa) após cinco passadas do trator + carreta.

Figure 3 - Cone penetrometer resistance (MPa) after 5 tractor + trailer passes.

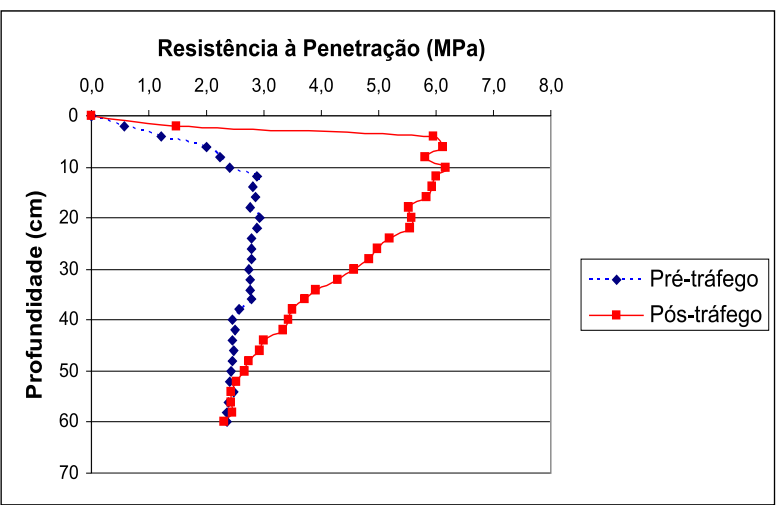

Figura 4 - Resistência à penetração do solo (MPa) após 10 passadas do trator + carreta.

Figure 4-Cone penetrometer resistance ( $\mathrm{MPa}$ ) after 10 tractor + trailer passes.

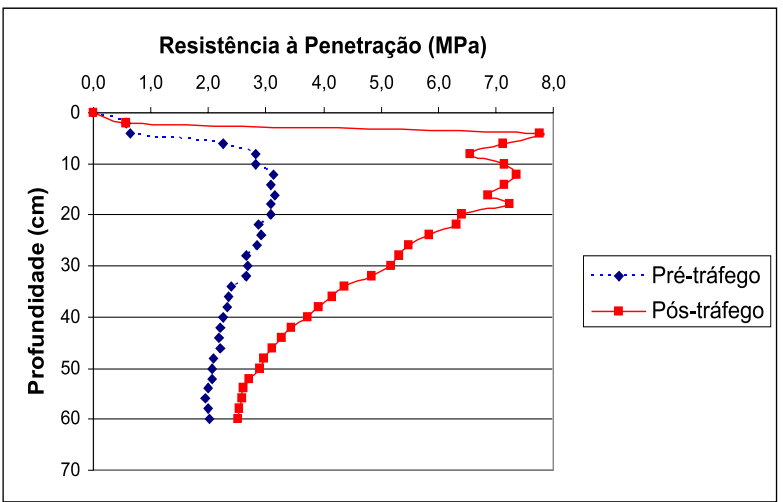

Figura 5 - Resistência à penetração do solo (MPa) após 20 passadas do trator + carreta.

Figure 5 - Cone penetrometer resistance (MPa) after 20 tractor + trailer passes. 


\subsection{Produtividade florestal}

Ao final de uma rotação de sete anos, foram determinados o volume médio por árvore e a produtividade por hectare, em todos os tratamentos e mais a testemunha. Em valores absolutos, a menor produtividade $\left(236,6 \mathrm{~m}^{3} \mathrm{ha}^{-1}\right)$ ocorreu no tratamento 5 , de maior freqüência de tráfego, enquanto a maior produtividade $\left(278,3 \mathrm{~m}^{3} \mathrm{ha}^{-1}\right)$ aconteceu no tratamento 2 , após três passadas do veículo (Tabela 2).

Não ocorreu diferença significativa entre os tratamentos com relação ao crescimento das árvores, demonstrando que, na situação do estudo, a compactação resultante do tráfego do veículo de extração de madeira não influenciou o desenvolvimento das árvores. De certa forma, esse resultado pode ter refletido o fato de o incremento na densidade do solo não haver atingido o limite considerado crítico ao desenvolvimento das plantas. Conforme discutido, as situações mais críticas, caracterizadas pela determinação da resistência à penetração do solo, foram devidas ao baixo teor de água no solo. Durante as diversas fases de crescimento, podem ter ocorrido alterações quanto a um menor impedimento à propagação do sistema radicular, principalmente nos períodos de maior presença de umidade no solo, o que provavelmente diluiu os efeitos da compactação resultante do tráfego do trator mais carreta.

Tabela 2 - Valores médios por tratamento de volume por árvore e produtividade por hectare

Table 2 -Average results by volume treatment per tree and forest yield per hectare

\begin{tabular}{ccc}
\hline Tratamentos & $\begin{array}{c}\text { Volume }\left(\mathrm{m}^{3}\right) / \\
\text { Árvore* }\end{array}$ & $\begin{array}{c}\text { Produtividade }\left(\mathrm{m}^{3}\right) / \\
\mathrm{Ha}^{*}\end{array}$ \\
\hline $\begin{array}{c}1 \\
(1 \text { passada) } \\
2\end{array}$ & $0,170 \mathrm{a}$ & $269,7 \mathrm{a}$ \\
$\begin{array}{c}(3 \text { passadas }) \\
3\end{array}$ & $0,173 \mathrm{a}$ & $278,3 \mathrm{a}$ \\
$\begin{array}{c}(5 \text { passadas) } \\
4\end{array}$ & $0,165 \mathrm{a}$ & $240,0 \mathrm{a}$ \\
$\begin{array}{c}(10 \text { passadas) } \\
5\end{array}$ & $0,171 \mathrm{a}$ & $253,7 \mathrm{a}$ \\
$\begin{array}{c}(20 \text { passadas) } \\
\text { Testemunha } \\
(\text { Sem tráfego })\end{array}$ & $0,154 \mathrm{a}$ & $236,6 \mathrm{a}$ \\
\hline
\end{tabular}

* Valores seguidos de mesma letra são semelhantes entre si, a 5\% de probabilidade.

\section{CONCLUSÕES}

Os resultados deste trabalho confirmaram as informações obtidas na literatura de que a maior parte da compactação de um solo, devido ao tráfego de veículos, ocorre já durante as primeiras passadas. Cerca de $80 \%$ do adensamento total do solo, ocorrido após 20 passadas do trator carregado de madeira, resultaram das cinco primeiras viagens desse equipamento, não havendo incremento significativo devido ao tráfego subseqüente.

Com isso, reforça-se a tese de se restringir o tráfego de veículos dentro do talhão na menor área possível, diminuindo-se a extensão dos prováveis efeitos da compactação sobre o povoamento florestal. Contudo, a compactação do solo não influenciou negativamente o crescimento das árvores, não sendo um fator preocupante para a espécie em questão, em função do tipo de solo, teor de água e tipo e carga do veículo de extração de madeira considerados neste estudo.

\section{AGRADECIMENTOS}

À Fundação de Amparo à Pesquisa do Estado de São Paulo(FAPESP) pelo financiamento deste projeto de pesquisa.

\section{REFERÊNCIAS}

FENNER, P. T. Compactação do solo. In: MACHADO, C. C. Colheita florestal. Viçosa, MG: Universidade Federal de Viçosa, 2002. p.375-396.

GEIST, J. M.; HAZARD, J. W.; SEIDEL K. W. Assessing physical conditions of some Pacific Northwest Volcanic ash soils after forest harvest.

Soil Science Society American Journal, v.53, p.946-50, 1989.

GREACEN, E. L.; SANDS, R. Compaction of forest soils. A review. Australian Journal of Soil Research, v.18, p.163-89, 1980.

HATCHELL, G. E.; RALSTON, C. W.; FOIL, R. R. Soil disturbance in logging. Journal of Forestry, n.68, p.772-775, 1970.

SANDS, R.; GREACEN, E. L.; GERARD, G. J. Compaction of sandy soils in radiata pine forests. I. A penetrometer study. Australian Journal of Soil Research, v.17, p.101-13, 1979.

SEIXAS, F.; KOURY, C. G. G.; RODRIGUES, F. A. Determinação da área impactada pelo tráfego de "forwarder" com uso de GPS. Scientia

Forestalis, n.63, p.178-187, 2003a.

R. Árvore, Viçosa-MG, v.31, n.6, p.1047-1052, 2007 
SEIXAS, F.; KOURY, C. G. G.; COSTA, L. G. Soil compaction and GPS determination of impacted area by skidder traffic. In: FOREST ENGINEERING CONFERENCE, 2, 2003, Växjö, Suécia.

Proceedings - Posters; Technique and Methods. Uppsala: Skogforsk, 2003b. p.124-129.
STOLF, R. Teoria e teste experimental de fórmulas de transformação dos dados de penetrômetro de impacto em resistência do solo. Revista Brasileira de Ciência do Solo, v.15, p.229-235, 1991. 